\title{
Analysis of KIT gene mutations in patients with melanoma of the head and neck mucosa: a retrospective clinical report
}

\author{
Ullyanov Bezerra Toscano de Mendonça ${ }^{1}$, Claudio Roberto Cernea², Leandro \\ Luongo Matos $^{2}$ and Roberto Rego Monteiro de Araujo Lima ${ }^{1}$ \\ ${ }^{1}$ Department of Head and Neck Surgery, Instituto Nacional do Cancer do Rio de Janeiro, Rio de Janeiro, Brazil \\ ${ }^{2}$ Department of Head and Neck Surgery, School of Medicine, University of São Paulo, Sao Paulo-SP, Brazil
}

Correspondence to: Ullyanov Bezerra Toscano de Mendonça, email: ullyanov@yahoo.com.br

Keywords: mucosal melanoma; KIT; c-kit; mutation; proto-oncogene

Received: November 23, $2016 \quad$ Accepted: March 22, $2018 \quad$ Published: May 01, 2018

Copyright: Mendonça et al. This is an open-access article distributed under the terms of the Creative Commons Attribution License 3.0 (CC BY 3.0), which permits unrestricted use, distribution, and reproduction in any medium, provided the original author and source are credited.

\section{ABSTRACT}

Unlike their cutaneous counterparts, head and neck mucosal malignant melanomas (HNMM) are more aggressive, and their prognostic markers have not been fully elucidated. This study, comprising 28 patients with HNMM, aimed to establish the relationship between different mutations and outcome, define the incidence of KIT mutations in HNMM, and identify the correlation among therapeutic options, histopathological findings, demographic data, and clinical response. Clinical analysis included patient characteristics, staging, primary and palliative treatments, and disease-free survival and overall survival (OS). Progression-free survival and OS were analyzed. Paraffin blocks were selected following histologic analyses, enabling DNA extraction. PCR amplification of exons 9, 11, 13, and 17, with different DNA concentrations, was performed. Patients were predominantly females (57\%) and aged 27-85 years. All patients underwent surgery; 17 received adjuvant radiotherapy, and recurrences occurred in $82 \%$ patients. Oncologic mutations in KIT were found in 7 of 7 tumors, 3 in exon 9, 3 in exon 11, and 1 in exon 13. Predictive factors for recurrence were mitotic rate, vascular invasion, and perineural spread. There were no significant differences in DFS and OS according to KIT mutation. Our study results suggest that some patients might benefit from appropriate targeted therapy with kinase inhibitors.

\section{INTRODUCTION}

The development of melanoma is a classic example of a neoplasm that progresses through different known stages. However, the key molecular event that triggers the progression of this neoplasm has still not been clarified, which explains why there is no specific therapy and why there have been so few advances in the multimodal therapy of this disease [1].

Somatic mutations in the KIT gene, which were identified in a small number of skin melanomas, appear to have a higher incidence in mucosal melanomas. Curtin et al. found mutations or an increase in the number of copies of the KIT in 39\% of mucosal melanomas. Moreover, there was an increase in KIT protein expression in mucosal melanomas, which supports their role in the progression of this melanoma subtype [2]. Given the evidence of a possible pathogenic role of the KIT gene in a number of mucosal melanomas, including those of the head and neck, screening for KIT aberrations may have diagnostic value, and the gene may represent a therapeutic target in these patients [3].

The identification of activating mutations in the KIT gene in patients with mucosal melanoma is important to improve knowledge of tumor biology and the design of clinical research protocols with imatinib. Because mucosal melanoma of the head and neck is a rare condition, the frequency of KIT mutations has not been characterized in these tumors. The objective of the present study was to evaluate the frequency of KIT mutations and their prognostic value in a significant number of head and neck mucosal melanomas [4]. 


\section{RESULTS}

Twenty-eight cases were included in the study. Summary information on each case is given in Table 1. Patient age ranged from 27 to 88 years, with a median of 59.5 years; 16 patients $(57.1 \%)$ were women; 24 patients $(85.7 \%)$ were white, and 4 patients were black. The majority of the tumors were classified as $\mathrm{T} 4(75 \%)$ and the majority of the cases were N0 or stage IV patients. Seven patients (25\%) had undifferentiated primary tumors, 17 patients $(60.5 \%)$ had tumors with a mitotic index higher than 10 mitoses $/ \mathrm{mm} 2$, and only 8 patients $(28.6 \%)$ exhibited amelanotic tumors.

\section{Analysis of KIT gene mutations}

Analysis of KIT gene mutations was possible in all of the 28 cases studied; 7 patients had KIT mutations and 21 patients had wild-type KIT. KIT mutations were most frequently detected in exon $11(42.8 \%)$ and exon 9 (42.9\%). Table 2 describes all the mutations found. Figure 1 shows a chromatogram of a mutation in exon 11 of the KIT gene, and loss of heterozygosity is represented in Figure 2. There was no significant relationship between the clinical and demographic variables and the presence of the KIT mutation ( $p>0.05$; Table 3$)$.

The DFS (disease-free-survival) rate for the cancer was $53.6 \%$ in 24 months and $37.5 \%$ in 60 months. The absence of adjuvant treatment and a mitotic index higher than 10 mitoses $/ \mathrm{mm} 2$ were associated with a higher probability of death $(p=0.05, \log$-rank test). The presence of vascular invasion and angiolymphatic dissemination were also statistically significant ( $p=0.04$ and $p=0.02$, respectively, log-rank test). In addition, there was a statistically significant relationship between recurrence and a mitotic index higher than 10 mitoses/ $\mathrm{mm} 2$, vascular invasion, angiolymphatic dissemination and perineural dissemination $(p=0.05, p=0.043$, $p=0.008$ and $p=0.034$, respectively, log-rank test). There were no statistical differences between the groups, and the presence of mutation did not play a role, either in protecting or promoting relapse or death.

\section{DISCUSSION}

Because of the rarity of this disease, only 28 cases were enrolled in the study. Kanda (2003) presented a study with a total of 54 cases from 3 different institutions, which demonstrates the rarity of the condition in the national context [5]. Therefore, much of the literature that exists on the subject addresses isolated cases and consists of retrospective analyses of series with relatively small sample sizes [6, 7].

Some peculiarities of the biological behavior of these tumors are extremely important: the anatomical location of the lesion, including its staging. Thus, some early-stage tumors may exhibit an aggressive behavior due to their location.

The historical results of HNMM treatment are disappointing. This soon led researchers to test new treatment strategies, such as the addition of chemotherapy or targeted therapy.

Defining prognostic parameters for HNMM is a much more complex task because the depth of invasionthe most important prognostic factor in skin melanomascannot be used due to the lack of histological points of reference similar to the papillary and reticular dermis.

Recent studies have evaluated the oncogenic role of KIT mutations in HNMM, as well as the benefits of therapy with tyrosine kinase inhibitors in these tumors. The results appear to be encouraging, showing significant benefits in survival time over chemotherapy and targeted therapy [8].

HNMM most frequently affects patients between the fifth and seventh decades of life, with more than $60 \%$ of patients belonging to this age group [9]. In this study, 16 (57\%) patients were aged over 60 . When we compared these 2 age groups, i.e., patients aged over 60 and those aged under 60 , with regard to disease recurrence and mortality, there was no significant difference $(p=0.38$ and $p=0.648$ ).

According to some authors there are no differences in the incidence of the location of HNMM, i.e., the incidence of tumors of the sinuses of the face and nose is equivalent to that of tumors of the oral cavity $[9,10]$. However, we found a higher incidence of tumors of the sinuses of the face $(75 \%)$ in our sample. This is due to factors related to the treatment; considering that in INCa more complex tumors are treated, we believe this is due to the sample selected.

Retrospective series did not demonstrate a relationship between the primary site of the tumor and both survival and local control $[11,12]$. This observation was confirmed in the present study. However, there are some reports of a poorer prognosis related to tumors originating in the sinuses of the face, probably because of the presence of locally advanced disease at diagnosis [13].

We used the TNM classification in the present study. The majority of tumors were classified as T4 (75\%) and the majority of patients had N0 neck and were considered stage IV. We did not find any differences in OS and DFS ( $p$ $=0.899$ and $p=0.523$, respectively). In the present study, we observed a mitotic index higher than 10 mitoses per field in $60.7 \%$ of the patients. This is an important result as it suggests a greater aggressiveness in these tumors. It is interesting to highlight that after analysis of DFS and OS, the mitotic index was found to be an independent prognostic factor for both end-points. OS in patients with a mitotic index higher than 10 mitoses per field was $36.4 \%$ in 48 months versus $51.5 \%$ in the other group $(p=0.05)$. Thompson et al. (2003) studied 115 patients with HNMM and obtained similar results, i.e., a poorer prognosis in 
Table 1: Summary of cases included in the study

\begin{tabular}{|c|c|c|c|c|c|c|c|}
\hline Case & Gender & Age & Ethnicity & Treatment & Relapse & SG (months) & KIT \\
\hline 1 & Female & 69 & White & $\mathrm{CX}+\mathrm{RXT}$ & Yes & 117 & Wild \\
\hline 2 & Female & 66 & White & $\mathrm{CX}+\mathrm{RXT}$ & Yes & 54 & Wild \\
\hline 3 & Female & 38 & White & $\mathrm{CX}$ & Yes & 11 & Wild \\
\hline 4 & Female & 88 & White & $\mathrm{CX}+\mathrm{RXT}$ & Yes & Still Alive & Wild \\
\hline 5 & Female & 64 & White & $\mathrm{CX}+\mathrm{RXT}$ & No & Still Alive & Mutated \\
\hline 6 & Female & 61 & White & $\mathrm{CX}+\mathrm{RXT}$ & No & Still Alive & Wild \\
\hline 7 & Female & 62 & White & $\mathrm{CX}+\mathrm{RXT}$ & Yes & 27 & Wild \\
\hline 8 & Female & 62 & White & $\mathrm{CX}$ & Yes & 29 & Wild \\
\hline 9 & Female & 39 & White & $\mathrm{CX}+\mathrm{RXT}$ & Yes & Still Alive & Wild \\
\hline 10 & Female & 62 & White & $\mathrm{CX}$ & No & Still Alive & Wild \\
\hline 11 & Female & 27 & White & $\mathrm{CX}$ & Yes & 10 & Wild \\
\hline 12 & Female & 59 & White & $\mathrm{CX}$ & Yes & Still Alive & Wild \\
\hline 13 & Female & 60 & White & $\mathrm{CX}$ & Yes & 8 & Wild \\
\hline 14 & Female & 76 & White & $\mathrm{CX}$ & Yes & 11 & Wild \\
\hline 15 & Female & 63 & White & $\mathrm{CX}$ & Yes & 14 & Wild \\
\hline 16 & Female & 69 & White & $\mathrm{CX}$ & Yes & 14 & Wild \\
\hline 17 & Male & 32 & White & $\mathrm{CX}+\mathrm{RXT}$ & Yes & 19 & Wild \\
\hline 18 & Male & 85 & White & $\mathrm{CX}+\mathrm{RXT}$ & Yes & 43 & Wild \\
\hline 19 & Male & 47 & White & $\mathrm{CX}$ & No & Still Alive & Wild \\
\hline 20 & Male & 39 & White & $\mathrm{CX}+\mathrm{RXT}$ & Yes & 64 & Wild \\
\hline 21 & Male & 53 & White & $\mathrm{CX}+\mathrm{RXT}$ & Yes & 99 & Mutated \\
\hline 22 & Male & 52 & White & $\mathrm{CX}+\mathrm{RXT}$ & Yes & Still Alive & Mutated \\
\hline 23 & Male & 62 & White & $\mathrm{CX}+\mathrm{RXT}$ & Yes & 27 & Wild \\
\hline 24 & Male & 51 & White & $\mathrm{CX}+\mathrm{RXT}$ & No & Still Alive & Wild \\
\hline 25 & Male & 40 & White & $\mathrm{CX}+\mathrm{RXT}$ & Yes & 15 & Mutated \\
\hline 26 & Male & 81 & Black & $\mathrm{CX}$ & Yes & 60 & Mutated \\
\hline 27 & Male & 69 & Black & $\mathrm{CX}+\mathrm{RXT}$ & Yes & 21 & Mutated \\
\hline 28 & Male & 76 & Black & $\mathrm{CX}+\mathrm{RXT}$ & Yes & 11 & Mutated \\
\hline
\end{tabular}

$\mathrm{CX}+\mathrm{RXT}=$ Surgical resection followed by adjuvante radiotherapy, $\mathrm{CX}=$ Exclusive surgical resection, $\mathrm{OS}=$ Overall survival.

Table 2: Distribution of the KIT mutations found

\begin{tabular}{lccc}
\hline Patient & Mutational status & Type of mutation & Note \\
\hline 5 & Exon 11 & V551I & Heterozygous \\
21 & Exon 11 & V551I & Heterozygous \\
22 & Exon 13 & L657F & Homozygous \\
25 & Exon 9 & L455M & Heterozygous \\
26 & Exon 11 & L576P & Heterozygous \\
27 & Exon 9 & S480F & Heterozygous \\
28 & Exon 9 & G499S & Heterozygous \\
\hline
\end{tabular}


the group with a high mitotic index $(p=0.026)$ [14]. In a recent work published by Moreno et al. (2010), 95\% of patients with a high mitotic index died from the HNMM, whereas patients with a mitotic index of less than 10 had a better response to systemic therapy [15]. In our sample, we found 8 cases $(28.6 \%)$ of amelanotic tumors, all confirmed by immunohistochemistry. Data from the literature suggest greater aggressiveness in amelanotic tumors, this being the only histopathological factor related to survival; no patient was alive after 48 months, compared with $47.6 \%$ survival in patients with pigmented tumors [15]. Our results did not confirm these data, but we had an OS of $55 \%$ in 48 months in patients with pigmented tumors, compared with $18.8 \%$ in those with amelanotic tumors. The explanation accepted for a poorer prognosis in amelanotic tumors is that they are associated with a delayed diagnosis.
In the sample, it was not possible to compare surgical treatment with other therapy modalities, because all the patients were submitted to resection. We obtained free margins in $82.15 \%$ of the patients; however, the finding of free margins had no impact on survival. Patients with positive surgical margins were 21 times more likely to die due to therapeutic failure, but we did not find this relation in the sample [16].

In local recurrent disease, and in the absence of metastatic dissemination, surgical removal should be considered, but the extent of the resection should be carefully planned. The chance of a successful surgical removal is less than $25 \%$, and the chances of distant metastases are increased [17].

The main motivation for performing this study was to investigate a marker with therapeutic potential for a

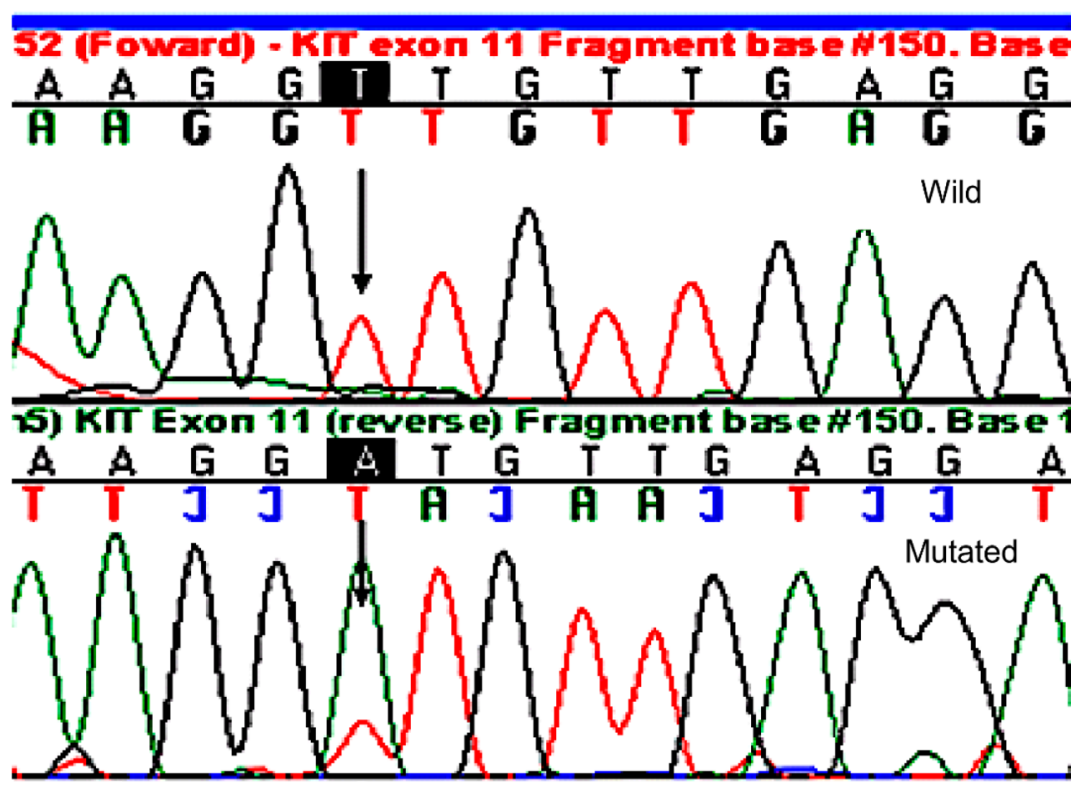

Figure 1: Chromatogram showing mutation in exon 11 of the gene KIT/L576P of a representative case (case 26).

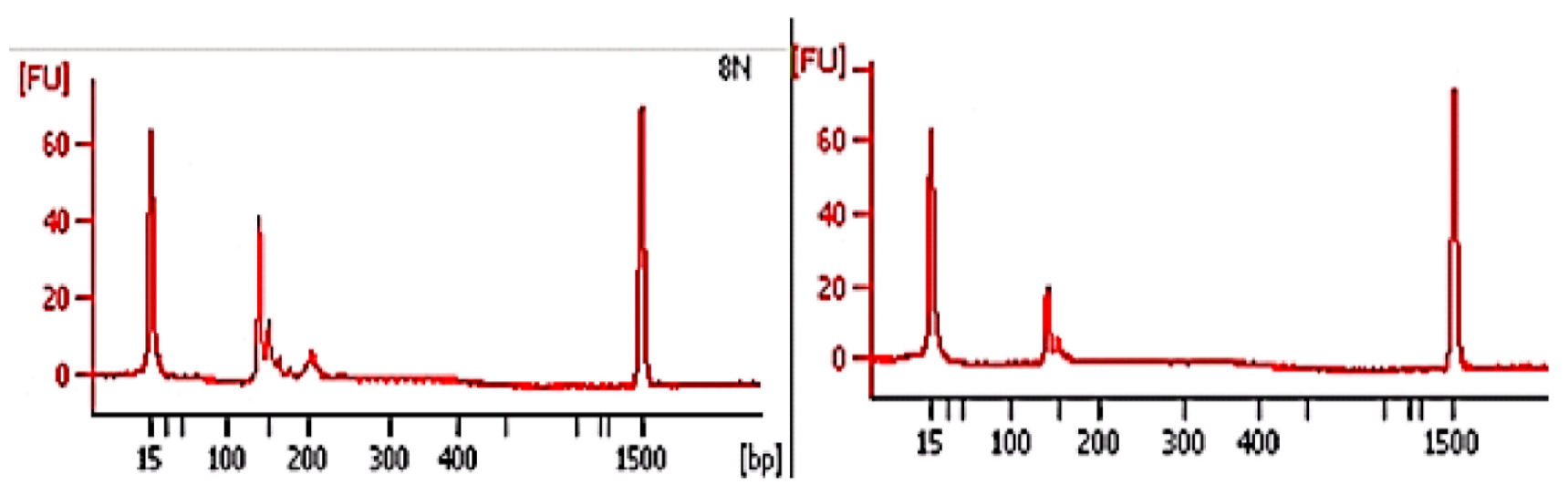

Figure 2: Electropherogram showing loss of heterozygosity of the KIT gene (HK 8810 Marker) (analysis using an Agilent 2100 bioanalyzer). 
Table 3: Clinical variables and their correlation with the KIT mutation

\begin{tabular}{|c|c|c|c|}
\hline \multirow[t]{2}{*}{ Variables } & \multicolumn{2}{|c|}{ KIT } & \multirow{2}{*}{$p^{*}$} \\
\hline & Wild $N=21(75 \%)$ & Mutation $N=7(25 \%)$ & \\
\hline \multicolumn{4}{|l|}{ Age } \\
\hline$>60$ & $12(42.9 \%)$ & $4(14.3 \%)$ & 0.666 \\
\hline$<60$ & $9(32.1 \%)$ & $3(10.7 \%)$ & \\
\hline \multicolumn{4}{|l|}{ Sex } \\
\hline Female & $12(42.9 \%)$ & $9(32.1)$ & 0.672 \\
\hline Male & $4(14.3 \%)$ & $3(10.7 \%)$ & \\
\hline \multicolumn{4}{|l|}{ Race } \\
\hline Whites & $18(64.3 \%)$ & $6(21.4 \%)$ & 0.747 \\
\hline Blacks & $3(10.7 \%)$ & $1(3.6 \%)$ & \\
\hline \multicolumn{4}{|l|}{ Smoking } \\
\hline Yes & $9(32.1 \%)$ & $4(14.3 \%)$ & 0.412 \\
\hline No & $12(42.9 \%)$ & $3(10.7 \%)$ & \\
\hline \multicolumn{4}{|l|}{ Alcohol use } \\
\hline Yes & $5(17.9 \%)$ & $2(7.1 \%)$ & 0.581 \\
\hline No & $16(57.1 \%)$ & $5(17.9 \%)$ & \\
\hline \multicolumn{4}{|l|}{ Location } \\
\hline Nasosinusal & $4(14.3 \%)$ & $4(14.3 \%)$ & 0.220 \\
\hline Oral cavity & 17 (60.7\%) & $3(10.7 \%)$ & \\
\hline
\end{tabular}

"Fischer's exact test.

disease that, although rare, is highly lethal. Moreover, there are few studies involving the research of KIT in HNMM, possibly as a result of the rarity of the disease.

The presence of KIT mutations in malignant melanomas has already been demonstrated in the literature, in particular in melanomas of the mucosa ( $21 \%$ of KIT mutations), acral melanomas (11\% of KIT mutations), and skin melanomas caused by chronic exposure to sunlight (17\% of KIT mutations) [2]. This suggests that KIT mutations have a role in the physiopathogeny and, therefore, are a potential therapeutic target in these subtypes of melanoma. In contrast, KIT mutations are rarely found in the largest subgroup of malignant melanomas, SM not associated with chronic exposure to sunlight: 1 in 100 cases studied by Willmore-Payne et al. (2005) [18]. Furthermore, phase II studies with imatinib in patients with SM, without KIT mutation analysis, were disappointing [19-21].

KIT mutations were evaluated in a selected group of patients with HNMM. Molecular analysis of KIT mutations was possible in 28 patients and showed mutations in 7 of them $(25 \%)$. This is consistent with the discoveries of Antonescu et al. (2007), and Rivera et al. (2008), who detected mutations in the KIT gene in 3 out of 20 patients $(15 \%)$ and in 4 out of 18 patients $(22 \%)$ with mucosal melanomas of the anal region and of the oral cavity, respectively [22-24]. Thus, KIT mutations occur in up to $20 \%$ of mucosal melanomas, regardless of the location of the primary tumor. Three mutations were detected in exon 11, 3 mutations in exon 9, and 1 mutation in exon 13; this distribution with a higher frequency of mutations in exons 11 and 13 is in line with the literature [25, 26]. Table 4 shows the prevalence of the mutation in various studies.

The role of the location of the KIT mutation in HNMM has been little studied. However, its prognostic value in GIST tumors has been shown in the literature: exon 11, which codifies the juxtamembrane domain, is involved in autoinhibition of the receptor; the mutations in this juxtamembrane domain impede this inhibitory function, increasing the dimerization of the receptor, independently of its activation. This location, in turn, is the most sensitive (responds better) to treatment with tyrosine kinase inhibitors. This indicates that HNMM is potentially sensitive to tyrosine kinase inhibitors [31].

In our results, there was not one mutation more frequent than the others: 2 cases V551I, 1 case L657F, 1 case L455M, 1 case L576P, 1 case S480F, and 1 case G499S. Although the available studies comprise a small number of patients and several studies have demonstrated the wide variety of mutations (Table 5 ). We attempted to 
Table 4: Summary of KIT mutations described in the literature

\begin{tabular}{lccc}
\hline Author & Year & Number of Patients & KIT Mutation \\
\hline Beadling et al. [27]. & 2008 & 29 & $8.4 \%$ \\
Carvajal et al. [28] & 2011 & 5 & $40 \%$ \\
Schoenewolf et al. [29]. & 2012 & 12 & $0 \%$ \\
Turri-Zanino et al. [7] & 2013 & 32 & $12.5 \%$ \\
Zebary et al. [30]. & 2013 & 56 & $3.6 \%$ \\
Present study. & 2015 & 28 & $25 \%$ \\
& Total & 162 & $9.8 \%$ \\
\hline
\end{tabular}

evaluate clinical-pathological characteristics and link them to KIT mutations. The results were discouraging, as none of the characteristics analyzed presented higher prevalence of mutation, despite the number of mutations identified being highly significant ( $8 / 28$ patients, $25 \%)$.

An interesting result was the distribution of mutations in terms of anatomical sites. In nasosinusal tumors, mutations were found in 4 cases (19\% of patients), whereas in the group of patients with mouth tumors mutations were found in 3 patients ( $75 \%$ of patients).

Our results suggest a higher incidence of mutations in melanomas of the oral cavity. This finding is not consistent with the literature data, in which mutations are more common in tumors of the sinuses [30]. No prognostic impact caused by the presence of the KIT mutation was found in the present study. We evaluated the relationship of the mutation with OS and DFS. DFS was $28.6 \%$ in 48 months in both groups, i.e., in patients with the mutation and in those who presented the wild-type KIT ( $p=0.771)$. SG was higher in patients with the wild-type gene, with a 5-year OS of $47.6 \%$, but without statistical significance $(p=0.935)$.

KIT mutations have been evaluated in various other tumors, and in some neoplasms they are an important prognostic factor. In gastrointestinal stromal tumors (GIST), the KIT mutation is an independent risk factor for OS and DFS; this relationship is so important that exon 11 is related to a better therapeutic response. GIST tumors are an example of the importance of KIT in the selection for treatment and prognosis. In patients with leukemia, KIT mutations can suggest a greater risk of relapse [35].

However, the prognostic importance of KIT mutations in melanoma was not evaluated in a series of adequate size. Our study confirmed the presence of $25 \%$ of mutation in HNMM, thus suggesting a route to study the pathophysiology of this tumor, with a focus on the MAPKs cascade and the inclusion of patients in clinical trials with KIT inhibitors.

In conclusion, the continual evaluation of KIT mutations is essential, in an attempt to identify biomarkers and improve the selection of patients for targeted therapy.

\section{MATERIALS AND METHODS}

For the formation of the group of this study, patients with head and neck mucosal melanomas were selected, enrolled, and treated at the Head and Neck Surgery Department of the National Cancer Institute (Instituto Nacional de Câncer - INCa). Cases without paraffin blocks of tumor tissue or cases with incomplete information on the treatment used were excluded. Molecular analyses of KIT mutations and of the pattern of response to the treatment used (surgical resection, radiotherapy, or a combination of the two) were considered for study in addition to clinical and pathology data. The study was approved by the Research Ethics Committee, under number 272/11.

\section{DNA extraction method}

DNA was extracted from tissue and embedded and fixed in paraffin using the MagNA Pure LC 2.0 semiautomated system (Roche Applied Science), according to the manufacturer's instructions. The procedure consisted of deparaffination with xylene, followed by graduated addition of ethane to eliminate any xylene residues.

Deparaffination with xylene was followed by digestion by proteinase K (BioAmerica, Inc, Homestead, FL, USA) using the Wizard ${ }^{\circledR}$ Genomi DNA purification kit (Promega, Madison, WI, USA). The extraction was confirmed by running a $5 \mu \mathrm{L}$ aliquot in $0.8 \%$ agarose gel in electrophoresis buffer (TBE 1X). To evaluate the integrity and concentration of the extracted DNA, a $1 \mu \mathrm{L}$ aliquot was analyzed in a ND-1000 spectrophotometer (NanoDrop Technologies Inc., Delaware, USA).

\section{KIT mutation analysis}

Mutational analysis of the gene was performed by Polymerase chain reaction (PCR) mplification and genome sequencing. The analysis began with exon 11 in the KIT gene, in which the majority of mutations are found $(70 \%$ of the described mutations), followed by exons 9,17 , 
Table 5: Correlation of molecular aberration

\begin{tabular}{|c|c|c|c|c|c|c|}
\hline Variable & $\begin{array}{c}\text { Carvajal et al. } \\
{[28]}\end{array}$ & $\begin{array}{c}\text { Guo et al. } \\
{[8]}\end{array}$ & Hodi et al. [32] & Lee et al. [33] & $\begin{array}{c}\text { Yun et al. } \\
{[34]}\end{array}$ & Present Study \\
\hline KIT mutation, $\mathrm{n}$ & 24 & 40 & 13 & 27 & 7 & 7 \\
\hline Exon 11 & $9(37.5 \%)$ & $17(42.5 \%)$ & $9(69.3 \%)$ & $17(62.9 \%)$ & 5 & $3 / 7(42.8)$ \\
\hline Exon 13 & $6(25 \%)$ & $9(22.5 \%)$ & $3(23.1 \%)$ & $6(22.2 \%)$ & 1 & $1 / 7(14.3)$ \\
\hline Exon 9 & NA & NA & NA & NA & NA & $3 / 7(42.8)$ \\
\hline Exon 17 & NA & NA & NA & NA & 1 & NA \\
\hline \multicolumn{7}{|l|}{$\begin{array}{l}\text { Specific } \\
\text { mutation type }\end{array}$} \\
\hline Exon 11 L576P & $7(77.8 \%)$ & NA & $3(33.3 \%)$ & $5(29.4 \%)$ & $2(40 \%)$ & $1(33.3 \%)$ \\
\hline Exon $13 \mathrm{~K} 642 \mathrm{E}$ & $4(66.6 \%)$ & NA & $3(100 \%)$ & $1(16.7 \%)$ & NA & NA \\
\hline Other Mutations & No & NA & $\begin{array}{l}\text { Exon } 11 \text { insetion } \\
\text { PYD577-582 } \\
\text { Exon } 17 \text { D820Y } \\
\text { Exon } 11 \text { V560D }\end{array}$ & $\begin{array}{l}\text { Exon } 17 \text { I817L } \\
\text { Exon } 11 \text { deletion } \\
\text { Exon } 11 \text { V559A }\end{array}$ & NA & $\begin{array}{l}\text { Exon } 11 \text { V551 } \\
\text { Exon } 13 \text { L657F } \\
\text { Exon } 9 \text { L455M, } \\
\text { S480F, G499S }\end{array}$ \\
\hline
\end{tabular}

NA, not available.

Table 6: Sequence of oligonucleotides used to amplify the KIT genes

\begin{tabular}{lcc}
\hline Gene & Target & Sequence $\mathbf{( \mathbf { 3 } ^ { \prime } \mathbf { - 5 } \mathbf { ) } )}$ \\
\hline KIT & Exon $9 \mathrm{~F}$ & TTCCTAGAGTAAGCCAGGGC \\
& Exon $9 \mathrm{R}$ & ACAGAGCCTAAACATCCCCT \\
& Exon $11 \mathrm{~F}$ & CCAGAGTGCTCTAATGACTGAGAC \\
& Exon $11 \mathrm{R}$ & AGGTGACATGGAAAGCCCCTG \\
& Exon $13 \mathrm{~F}$ & CTGCATGCGCTTTGACATCAG \\
& Exon $13 \mathrm{R}$ & CTAGCATTGCCAAAATCATATT \\
& Exon $17 \mathrm{~F}$ & GTTTTCTTTTCTCCTCCAACCT \\
Exon $17 \mathrm{R}$ & CCTTTGCAGGACTGTCAAGC \\
\hline
\end{tabular}

Legend: F: Sense; R: Antisense.

and 13. It should be emphasized that the mutations are exclusive.

Exons 9, 11, 13, and 17 of the KIT gene were amplified using the primer pairs described in Table 6. The purified PCR products were prepared for genome sequencing, using a final volume of $7.5 \mu 1$ (solution containing primer, DNA, and milli-Q water). Sequencing was performed using the Sanger method, and the software used in the analysis of the results was the automated sequencer ABI PRISMTM 377 (Applied Biosystems Foster City, California, USA), which interprets the results by titrating each base in relation to the intensity of the fluorescent compound, denominating 4 specific colors. The software used in the analysis of sequencing uses the same 4 specific colors for each base. By convention, A (adenine) was labeled as green, $\mathrm{C}$ (cytosine) as blue, $\mathrm{T}$ (Thymine) as red, and G (guanine) as black, in the electropherogram image.

\section{Statistical analysis}

The statistical analyses were performed using the SPSS software, version 18.0 (SPSS Inc., Chicago, IL, USA). Overall survival (OS) (defined as the time between the start date of the treatment and the date of death) and disease-free survival (DFS) (defined as the time between treatment and recurrence) were estimated by the KaplanMeier method, and the survival curves were compared using the log-rank test. Univariate analysis was performed to evaluate the association between the variables age, sex, primary tumor site, mutational status of the KIT gene, and DFS. A $p$ value $\leq 0.05$ was considered statistically significant.

\section{CONFLICTS OF INTEREST}

None. 


\section{REFERENCES}

1. Winnenpenninckx V, Lazar V, Michiels S, Dessen P, Stas M, Alonso SR, Avril M, Romero PLO, Robert T, Balacescu O, Eggermont AMM, Lenoir G, Sarasin A, et al. Gene expression profiling of primary cutaneous melanoma and clinical outcome. J Natl Cancer Inst. 2006; 98:472-82. https://doi.org/10.1093/jnci/djj103.

2. Curtin JA, Busam K, Pinkel D, Bastian B. Somatic activation of KIT in distinct subtypes of melanoma. J Clin Oncol. 2006; 24:4340-6. https://doi.org/10.1200/ JCO.2006.06.2984.

3. Davies H, Bignell GR, Cox C, Stephens P, Edkins S, Clegg S, Teague J, Woffendin H, Garnett MJ, Bottomley W, Davis N, Dicks E, Ewing R, et al. Mutations of the BRAF gene in human cancer. Nature. 2002; 417:949-54. https://doi. org/10.1038/nature00766.

4. Chin L, Garraway LA, Fisher DE. Malignant melanoma: genetics and therapeutics in the genomic era. Genes Dev. 2006; 20:2149-82. https://doi.org/10.1101/gad.1437206.

5. Kanda JL. Mucosal melanoma of head and neck: survival analysis and clinicopathological prognostic factors. [Article in Portuguese] (Doctoral dissertation) São Paulo; s.n; 2003. Available from http://repositorio.unifesp.br/ handle/11600/19753.

6. Rinaldo A, Shaha AR, Patel SG, Ferlito A. Primary mucosal melanoma of the nasal cavity and paranasal sinuses. Acta Otolaryngol. 2001; 121:979-82. https://doi. org/10.1080/00016480127369.

7. Turri-Zanoni M, Medicina D, Lombardi D, Ungari M, Balzarini P, Rossini C, Pellegrini W, Battaglia P, Capella C, Castelnuovo P, Palmedo G, Facchetti F, Kutzner H, et al. Sinonasal mucosal melanoma: molecular profile and therapeutic implications from a series of 32 cases. Head Neck. 2013; 35:1066-1077. https://doi.org/10.1002/ hed.23079.

8. Guo J, Si L, Kong Y, Flaherty KT, Xu X, Zhu Y, Corless CL, Li L, Li H, Sheng X, Cui C, Chi Z, Li S, et al. Phase II, open-label, single-arm trial of imatinib mesylate in patients with metastatic melanoma harboring c-Kit mutation or amplification. J Clin Oncol. 2011; 29:2904-9. https://doi. org/10.1200/JCO.2010.33.9275.

9. Chang AE, Karnell LH, Menck HR. The National Cancer Data Base report on cutaneous and noncutaneous melanoma: a summary of 84,836 cases from the past decade. Cancer. 1998; 83:1664-78. https://doi.org/10.1002/(SICI)10970142(19981015)83:8\%3C1664::AID-CNCR23\%3E3.0.CO; $2-\mathrm{G}$.

10. Gal TJ, Silver N, Huang B. Demographics and treatment trends in sinonasal mucosal melanoma. Laryngoscope. 2011; 121:2026-33. https://doi.org/10.1002/lary.21925.

11. Nandapalan V, Roland NJ, Helliwell TR, Williams EM, Hamilton JW, Jones AS. Mucosal melanoma of the head and neck. Clin Otolaryngol Allied Sci. 1998; 23:107-16. https://doi.org/10.1046/j.1365-2273.1998.00099.x.

12. Owens JM, Roberts DB, Myers JN. The role of postoperative adjuvant radiation therapy in the treatment of mucosal melanomas of the head and neck region. Arch Otolaryngol Head Neck Surg. 2003; 129:864-68. https:// doi.org/10.1001/archotol.129.8.864.

13. Haerle SK, Soyka MB, Fischer DR, Murer K, Strobel K, Huber GF, Holzmann D. The value of 18F-FDG-PET/ CT imaging for sinonasal malignant melanoma. Eur Arch Otorhinolaryngol. 2012; 269:127-33. https://doi. org/10.1007/s00405-011-1664-1.

14. Thompson LD, Wieneke JA, Miettinen M. Sinonasal tract and nasopharyngeal melanomas: a clinicopathologic study of 115 cases with a proposed staging system. Am J Surg Pathol. 2003; 27:594-611.

15. Moreno MA, Hanna EY. Management of mucosal melanomas of the head and neck: did we make any progress? Curr Opin Otolaryngol Head Neck Surg. 2010; 18:101-6. https://doi.org/10.1097/MOO.0b013e3283374d31.

16. Penel N, Mallet Y, Mirabel X, Van JT, Lefebvre JL. Primary mucosal melanoma of head and neck: prognostic value of clear margins. Laryngoscope. 2006; 116:993-5. https://doi. org/10.1097/01.mlg.0000217236.06585.a9.

17. Moreno MA, Roberts DB, Kupferman ME, DeMonte F, El-Naggar AK, Williams M, Rosenthal DS, Hanna EY. Mucosal melanoma of the nose and paranasal sinuses, a contemporary experience from the M. D. Anderson Cancer Center. Cancer. 2010; 116:2215-23. https://doi.org/10.1002/ cncr.24976.

18. Willmore-Payne C, Holden JA, Tripp S, Layfield LJ. Human malignant melanoma: detection of BRAF- and c-kit-activating mutations by high-resolution amplicon melting analysis. Hum Pathol. 2005; 36:486-93.

19. Ugurel S, Hildenbrand R, Zimpfer A, La Rosee P, Paschka P, Sucker A, Keikavoussi P, Becker JC, Rittgen W, Hochhaus A, Schadendorf D. Lack of clinical efficacy of imatinib in metastatic melanoma. Br J Cancer. 2005; 92:1398-405. https://doi.org/10.1038/sj.bjc.6602529.

20. Wyman K, Atkins MB, Prieto V, Eton O, McDermott DF, Hubbard F, Byrnes C, Sanders K, Sosman JA. Multicenter phase II trial of high- dose imatinib mesylate in metastatic melanoma: significant toxicity with no clinical efficacy. Cancer. 2006; 106:2005-11. https://doi.org/10.1002/ cncr. 21834.

21. Becker JC, Brocker EB, Schadendorf D, Ugurel S. Imatinib in melanoma: a selective treatment option based on KIT mutation status? J Clin Oncol. 2007; 25:e9. https://doi. org/10.1200/JCO.2006.08.9664.

22. Antonescu CR, Busam KJ, Francone TD, Wong GC, Guo T, Agaram NP, Besmer P, Jungbluth A, Gimbel M, Chen CT, Veach D, Clarkson BD, Paty PB, Weiser MR. L576P KIT mutation in anal melanomas correlates with KIT protein 
expression and is sensitive to specific kinase inhibition. Int J Cancer. 2007; 121:257-64. https://doi.org/10.1002/ ijc. 22681 .

23. Rivera RS, Nagatsuka H, Gunduz M, Cengiz B, Gunduz E, Siar CH, Tsujigiwa H, Tamamura R, Han KN, Nagai $\mathrm{N}$. C-kit protein expression correlated with activating mutations in KIT gene in oral mucosal melanoma. Virchows Arch. 2008; 452:27-32. https://doi.org/10.1007/ s00428-007-0524-2.

24. Rivera RS, Nagatsuka H, Siar CH, Gunduz M, Tsujigiwa H, Han PP, Katase N, Tamamura R, Ng KH, Naomoto Y, Nakajima M, Nagai N. Heparanase and vascular endothelial growth factor expression in the progression of oral mucosal melanoma. Oncol Rep. 2008; 19:657-61.

25. Tate G, Tajiri T, Suzuki T, Mitsuya T. Mutations of the KIT gene and loss of heterozygosity of the PTEN region in a primary malignant melanoma arising from a mature cystic teratoma of the ovary. Cancer Genet Cytogenet. 2009; 190:15-20. https://doi.org/10.1016/j. cancergencyto.2008.11.002.

26. Daniotti M, Ferrari A, Frigerio S, Casieri P, Miselli F, Zucca E, Collini P, Della Torre G, Manoukian S, Peissel B, Bono A, Santinami M, Parmiani G, et al. Cutaneous melanoma in childhood and adolescence shows frequent loss of INK4A and gain of KIT. J Invest Dermatol. 2009; 129:1759-68. https://doi.org/10.1038/jid.2008.422.

27. Beadling C, Jacobson-Dunlop E, Hodi FS, Le C, Warrick A, Patterson J, Town A, Harlow A, Cruz F 3rd, Azar S, Rubin BP, Muller S, West R, et al. KIT gene mutations and copy number in melanoma subtypes. Clin Cancer Res. 2008; 14:6821-8. https://doi.org/10.1158/1078-0432. CCR-08-0575.

28. Carvajal RD, Antonescu CR, Wolchok JD, Chapman PB, Roman RA, Teitcher J, Panageas KS, Busam KJ, Chmielowski B, Lutzky J, Pavlick AC, Fusco A, Cane L, et al. KIT as a therapeutic target in metastatic melanoma. JAMA. 2011; 305:2327-34. https://doi.org/10.1001/ jama.2011.746.
29. Schoenewolf NL, Bull C, Belloni B, Holzmann D, Tonolla S, Lang R, Mihic-Probst D, Andres C, Dummer R. Sinonasal, gen ital and acrolentiginous melanomas show distinct characteristics of KIT expression and mutations. Eur J Cancer. 2012; 48:1842-52. https://doi.org/10.1016/j. ejca.2012.02.049.

30. Zebary A, Jangard M, Omholt K, Ragnarsson-Olding B, Hansson J. KIT, NRAS and BRAF mutations in sinonasal mucosal melanoma: a study of 56 cases. Br J Cancer. 2013; 109:559-64. https://doi.org/10.1038/bjc.2013.373.

31. Lasota J, Miettinen M. Clinical significance of oncogenic KIT and PDGFRA mutations in gastrointestinal stromal tumors. Histopathology. 2008; 53:245-66. https://doi. org/10.1111/j.1365-2559.2008.02977.x.

32. Hodi FS, Corless CL, Giobbie-Hurder A, Fletcher JA, Zhu M, Marino-Enriquez A, Friedlander P, Gonzalez R, Weber JS, Gajewski TF, O'Day SJ, Kim KB, Lawrence D, et al. Imatinib for melanomas harboring mutationally activated or amplified KIT arising on mucosal, acral, and chronically sun-damaged skin. J Clin Oncol. 2013; 31:3182-90. https:// doi.org/10.1200/JCO.2012.47.7836.

33. Lee SJ, Kim TM, Kim YJ, Jang KT, Lee HJ, Lee SN, Ahn MS, Hwang IG, Lee S, Lee MH, Lee J. Phase II trial of nilotinib in patients with metastatic malignant melanoma harboring KIT gene aberration: A multicenter trial of Korean Cancer Study Group (UN10-06). Oncologist. 2015; 20:1312-9. https://doi.org/10.1634/ theoncologist.2015-0161.

34. Yun J, Lee J, Jang J, Lee EJ, Jang KT, Kim JH, Kim KM. KIT amplification and gene mutations in acral/mucosal melanoma in Korea. APMIS. 2011; 119:330-5. https://doi. org/10.1111/j.1600-0463.2011.02737.x.

35. Singer S, Rubin BP, Lux ML, Chen CJ, Demetri GD, Fletcher CD, Fletcher JA. Prognostic value of KIT mutation type, mitotic activity, and histologic subtype in gastrointestinal stromal tumors. J Clin Oncol. 2002; 20:3898-905. https://doi.org/10.1200/JCO.2002.03.095. 